\title{
Socio-economic inequality in anaemia among men in India: a study based on cross-sectional data
}

\author{
Pradeep Kumar ${ }^{1}$, Himani Sharma ${ }^{1}$ and Debashree Sinha ${ }^{2^{*}}$
}

\begin{abstract}
Background: Undernutrition is a serious matter of public health concern in India. Existing studies, policies and programs focus on women and children thereby ignoring men in policymaking. This study examines the socioeconomic inequality in anaemia levels among men in India and tries to decompose the factors behind it.

Methods: The fourth round of National Family Health Survey is used to fulfill the study objectives. The outcome variable of the study is men having anaemia or not. The study uses bivariate and multivariate techniques to identify the factors associated with the outcome variable. Further, concentration index and concentration curve are calculated to measure the socio-economic inequality in anaemia among men in India.

Results: The results indicate that majority of the socio-economic related inequality is explained by wealth quintile followed by geographical regions of India, body mass index and educational attainment. The results also emphasize that older men belong to the high-risk groups. Moreover, the likelihood of anaemia is $40 \%$ more likely among men who belonged to East region and 25\%, 13\% and $7 \%$ less likely among those who belonged to Northeast, West and South region compared to those who belonged in the North region of the country.
\end{abstract}

Conclusion: Existing policies on anaemia should include men to achieve an anaemia free India. Individual education and awareness should be encouraged to improve nutritional status.

Keywords: Anaemia, Men, Socio-economic inequality, Concentration index, India

\section{Background}

Despite the necessary provisions taken to improve the indicators of nutrition and related health matters over the past few decades, the problem of undernutrition remains as a serious matter of public health concern in the underdeveloped and developing nations. The problem of malnutrition and undernutrition is multifaceted, comprising of stunting, wasting, overweight and anaemia, gripping its force on the global community. According to the Global Nutrition Report 2017, 125

\footnotetext{
*Correspondence: debashreesinha04@gmail.com

2Department of Development Studies, International Institute for Population Sciences, Mumbai, Maharashtra 400088, India

Full list of author information is available at the end of the article
}

countries face the burden of anaemia wherein, six countries with anaemia only; 38 with anaemia and stunting; 52 with anaemia and overweight; 29 with anaemia, stunting and overweight [1]. The burden of anaemia affects $27 \%$ of the world's population in which the developing countries alone account for more than $89 \%$ of the burden [2]. A leading data and analytics company GlobalData, in its epidemiological analysis, revealed that India has the highest prevalence of anaemia at 39.86\% among the 16 major pharmaceutical markets [3]. As per the estimates of the World Health Organization (WHO), anaemia is a significant public health problem among $12.7 \%$ of the males globally [4]. In addition to this, according to the National Family Health Survey-4, anaemia

C C The Author(s). 2021 Open Access This article is licensed under a Creative Commons Attribution 4.0 International License, which permits use, sharing, adaptation, distribution and reproduction in any medium or format, as long as you give appropriate credit to the original author(s) and the source, provide a link to the Creative Commons licence, and indicate if changes were made. The images or other third party material in this article are included in the article's Creative Commons licence, unless indicated otherwise in a credit line to the material. If material is not included in the article's Creative Commons licence and your intended use is not permitted by statutory regulation or exceeds the permitted use, you will need to obtain permission directly from the copyright holder. To view a copy of this licence, visit http://creativecommons.org/licenses/by/4.0/ The Creative Commons Public Domain Dedication waiver (http://creativecommons.org/publicdomain/zero/1.0/) applies to the data made available in this article, unless otherwise stated in a credit line to the data. 
prevalence was $23 \%$ in $2015-16$ among men in India, a bare change from $24 \%$ in 2005-06 [5]. The situation of anaemia stands alarming not just in India but also in other neighboring countries such as Myanmar, Cambodia, Bangladesh and Nepal as well [6].

In these middle income countries of South Asia, anaemia hampers the economic productivity to a certain extent [7]. However, studies have found inconsistent association between economic growth and reduction of malnutrition [8]. According to Alderman \& Linnemayr, the rates of anemia do get influenced by economic growth but the increment is 'anaemic' in itself. Despite vigorous economic developments, the rate of decline of anaemia is modest. Although the rates of anemia in the population do decrease as the income increases, the decline is sluggish [7].

Anaemia is a grave public health concern affecting all the segments of society. It is generally defined as a condition in which the hemoglobin concentration is less than a defined level, which subsequently results in the decreased oxygen-carrying capacity of blood [9]. Anaemia in women is a serious cause of concern as blood loss, maternity problems and many more. Similarly, it hampers cognitive development in children. However, in the case of men, anaemia is not recognized as a disease or a significant problem due to concealed and ambiguous symptoms [10].

An approximate of a quarter of men aged 15-54 reported having anaemia, both in India in general and in the EAG states, indicating it is as considerable a problem as it is among women and children. Figure 1 depicts the prevalence of anaemia in men and women in the year 2015-16. It is evident that women are more anaemic than men, though the prevalence of anemia among men has also been high enough to be treated as a public health issue. Although, the problems faced by men due to anaemia are a little different in nature from women, they do hamper their life in general. Studies have shown that among adult males, iron deficiency anaemia hampers the productivity and physical capacity and the significant symptoms comprise of tiredness, lethargy and fatigue $[10,11]$. A qualitative study conducted in the rural area of Haryana revealed that the knowledge and attitude toward dietary factors of anaemia were found to be conflicting among men. Despite being aware of the importance of good diet and green leafy vegetables, the study participants stated easy availability of dairy products and unaffordability of green leafy vegetables and fruits as the two main reasons of low intake of green leafy vegetables [12].

The National Policy of 1993 was a dedicated approach towards overall development and wellbeing of the citizens in India and took a bold step towards curbing the rates of anemia in the country. However, it focused upon improving the nutritional status of the most fragile and vulnerable section, i.e., women and children. Women and children were considered as nutritionally at risk and men were not even in the radar of this policy. Various national and state level policies have been formulated from time to time but they neglected male population in the country. For instance, Integrated Child Development Services (ICDS) in 1925 and Mid-Day Meal Scheme in 1962-63, the Special Nutrition Programme, Balwadi Nutrition Programme and National Anaemia Prophylaxis Programme in 1970-71, all were centered towards preventing anaemia among mothers and children of different age groups [13]. Similarly, the National Iron+ Initiative launched by the Adolescent Division of the Ministry of Health and Family Welfare (MoHFW), Government of India was intended to reduce anemia among the vulnerable groups such as pregnant women, infants, young children and adolescents by providing supplementation of Iron \& Folic Acid [14]. Other initiatives which neglected men over women like Anaemia Mukt Bharat also were based on the idea of reducing of anemia prevalence among young children 6-59

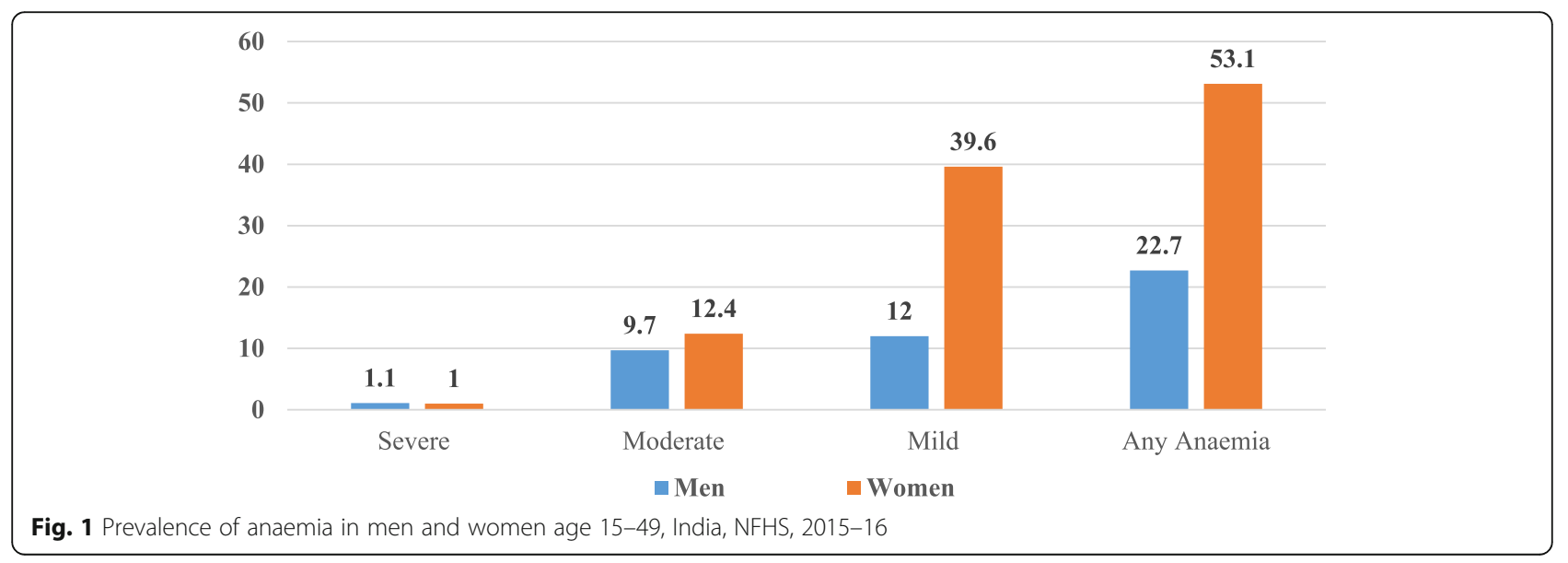


months and women of the reproductive age group in India $[15,16]$.

Numerous studies have taken up the theme of addressing the gender gap in adult malnutrition in India $[17,18]$. The surplus amount of studies have focused on the issues of anaemia among women, children and adolescents $[17,19,20]$. Either most of the studies on anaemia have always been limited to women and children, or they have been mostly conducted in the underdeveloped countries and developing countries, other than India [21-23]. Anaemia has been a constant issue of struggle among men, both in terms of prevalence and economic impact, it has received little research and policy attention [24]. There is a dearth of studies about the issue of anaemia among men in India.

Moreover, the existing few studies do not reveal much about the dynamics of associated factors regarding anaemia and the inherent socio-economic inequality in it. The policies and programmes catered to combat anaemia are focused on women and children and hence ignoring the men in policymaking. This study sought to examine the inequality in anaemia levels among men and to decompose the factors behind this process among the male population in India.

\section{Data and methods}

\section{Data}

National representative cross-sectional data from the fourth round of the National Family Health Survey (NFHS-4), conducted in India in 2015-16, was used for this study. The survey collected demographic, socioeconomic, and health information from a nationally representative probability sample of 699,868 women aged (15-49 years) and 112,122 men aged (15-54 years) with a response $97 \%$ and $92 \%$ respectively, residing in 601,509 households. NFHS-4 adopted a stratified two-stage sampling procedure and covered all 36 states and union territories. Full details of the survey have been published [5] and are available at https://dhsprogram.com/data/ available-datasets.cfm. Additionally, the survey designed to provide vital estimates of clinical, anthropometric and biochemical $(\mathrm{CAB})$ measurements; prevalence of malnutrition, anaemia, hypertension, HIV, and high blood glucose levels through a series of biomarker tests and measurements.

The Biomarker Questionnaire covered measurements of height, weight, and haemoglobin for children, and measurements of height, weight, haemoglobin, blood pressure, and random blood glucose for women aged 15-49 years and men aged 15-54 years (in the state module subsample of households only). The adequate sample size for this study was 108,261 men aged 15-54 years. We removed the missing information for better estimates.

\section{Outcome variable}

\section{Anaemia testing}

In NFHS-4, blood specimens for anaemia testing were not collected by the authors but by trained health investigators with the consent of the respondents. Blood samples were drawn from a drop of blood taken from a finger prick and collected in a microcuvette. Haemoglobin analysis was conducted on-site with a batteryoperated portable HemoCueHb 201+ analyser. More details on how haemoglobin was measured can be found in the national report http://rchiips.org/nfhs/pdf/NFHS4/ India.pdf [5]. Following WHO's recommendations, men were categorised as anaemic in any form if their haemoglobin concentration was lower than $13.0 \mathrm{~g} / \mathrm{dL}$, mildly anaemic if it was $12.0-12.9 \mathrm{~g} / \mathrm{dL}$, moderately anaemic if it was $9.0-11.9 \mathrm{~g} / \mathrm{dL}$, and severely anaemic if it was lower than $8.9 \mathrm{~g} / \mathrm{dL}$. For the analysis purpose, the study created a dichotomous variable coded as 1 'anaemia' if men's haemoglobin level was lower than 13.0 g.dL and 0 'not anaemic' if the haemoglobin level was higher than 13.0 g.dL among men.

\section{Exposure variables}

Given the dearth of research on men's anaemia, the exposure variables were selected based on literature available on the current matter $[12,25]$. These included age of men $(15-19,20-24,25-29,30-34,35-39,40-44$, 45-49 and 50-54 years), marital status (never married and currently married), men's educational level (no education, primary, secondary and higher), men's exposure to mass media (how often they read newspapers, listened to the radio and watched television; responses on the frequencies were: almost every day, at least once a week, less than once a week,or not at all; men were considered to have any exposure to mass media if they had exposure to any of these sources and as having no exposure if they responded with 'not at all' for all the three sources of media), body mass index (underweight: $<18.5 \mathrm{~kg} / \mathrm{m}^{2}$, normal: $18.5-24.99 \mathrm{~kg} / \mathrm{m}^{2}$, and overweight: $\geq 25 \mathrm{~kg} / \mathrm{m}^{2}$ ), tobacco use (if men used any forms of tobacco (smoke/ smokeless) coded as ' 1 ' yes and 0 'no' otherwise), and caste [scheduled caste (SCs), scheduled tribe (STs), other backward class $(\mathrm{OBC})$, and others (including all privileged caste groups)]. Other predictors were religion [Hindu, Muslim and others (including Christian, Sikh, Buddhist/Neo-Buddhist, Jain, Jewish, Parsi/Zoroastrian, no religion, and other)], and wealth index (poorest, poorer, middle, richer and richest). For the calculation of wealth index, households were given scores based on the number and kinds of consumer goods they own, ranging from a television to a bicycle or car, and housing characteristics such as source of drinking water, toilet facilities, and flooring materials. These scores were derived using principal component analysis. National wealth 
quintiles were compiled by assigning the household score to each usual (de jure) household member, ranking each person in the household population by their score, and then dividing the distribution into five equal categories, each with $20 \%$ of the population [5] . Place of residence was given as rural and urban in the survey. Geographical regions were categorized as North, Central, East, Northeast, West, and South.

\section{Statistical analysis}

Descriptive statistics were used to show the distribution of the study population. Further, bivariate and multivariate logistic regression analysis was used to identify the factors associated with the outcome variable. A Chi-square test was performed to understand the association between outcome variable and predictors. When exploring the association between the prevalence of anemia and men's background characteristics, for ordered categorical characteristics, such as wealth index and education level, Cochran Armitage trend test was used. The analysis of the dataset was carried out after assigning survey weight available in the data set. Moreover, Variance Inflation Factor (VIF) was estimated to check for multicollinearity and 10 is taken as the cut-off value [26].

\section{Concentration index}

Existing literature on measuring socio-economic inequality on various dimensions uses Concentration Index and Concentration curve [27-29]; hence we tried to adopt those methodologies in the present paper. The wealth quintile was the critical variable to measure the economic status of the household. The study used a wealth score for decomposition analysis and the calculation of Concentration Index (CI). The study divided ranking into five equal categories, each comprising $20 \%$ population. Concentration Index (CI) and Concentration curve (CC) was calculated to measure the socioeconomic inequality in anaemia among men in India. Concentration index represents the magnitude of inequality by measuring the area between the concentration curve and line of equality and calculated as twice the weighted covariance between the outcome and fractional rank in the wealth distribution divided by the variable mean.

The concentration index can be written as follows:

$$
C=\frac{2}{\mu} \operatorname{cov}\left(y_{i}, R_{i}\right)
$$

Where $\mathrm{C}$ is the concentration index; $y_{i}$ is the outcome variable index; $\boldsymbol{R}$ is the fractional rank of individual $\boldsymbol{i}$ in the distribution of socioeconomic position; $\boldsymbol{\mu}$ is the mean of the outcome variable of the sample, and cov denotes the covariance [30]. The index value lies between -1 to +1 .

If the curve lies above the line of equality, the concentration index takes a negative value, indicating a disproportionate concentration of inequality among the poor (pro-rich). Conversely, if the curve lies below the line of equality, the concentration index takes a positive value, indicating a disproportional concentration of inequality among the rich (pro-poor). In the absence of socioeconomic related inequality, the concentration index is zero. The value of CI quantifies the extent of socio-economic inequality. The larger the absolute value, the greater the inequalities.

\section{Decomposition of the concentration index}

The study used Wagstaff decomposition analysis in decomposing the concentration index. Wagstaff's decomposition demonstrated that the concentration index could be decomposed into the contributions of each factor to the income-related inequalities [31]. Each contribution is the outcome of the sensitivity of health concerning that socioeconomic factor and the extent of income-related inequality in that factor. Based on the linear regression relationship between the outcome variable $y_{i}$, the intercept $\alpha$, the relative contribution of $x_{k i}$ and the residual error $\varepsilon_{i}$

$$
y_{i}=\alpha+\sum \beta_{k} x_{k i}+\varepsilon_{i}
$$

Where $\varepsilon_{i}$ is an error term, given the relationship between $y_{i}$ and $x_{k i}$, the CI for $\mathrm{y}(\mathrm{C})$ can be rewritten as

$$
C=\sum\left(\frac{\beta_{k} \bar{x}_{k}}{\mu}\right) C_{k}+\frac{G C \varepsilon}{\mu} / \mu
$$

Where $\mu$ is the mean of $y_{i}, \bar{x}_{k}$, is the mean of $x_{k}, \beta_{k}$ is the coefficient from a linear regression of outcome variable, $C_{k}$ is the concentration index for $x_{k}$ (defined analogously to $\mathrm{C}$, and $\mathrm{GC}_{\varepsilon}$ is the generalized concentration index for the error term $\left(\varepsilon_{i}\right)$.

Here $C$ is the outcome of two components: First, the determinants or 'explained' factors, which are equivalent to the weighted accumulation of the concentration indices of the regressor, where a one-unit change in the outcome variable is to be associated with the one-unit change in the explanatory variable. The explained factors indicate that the proportion of inequalities in the outcome (anaemia among men) variable is explained by the selected explanatory factors, i.e., $\mathbf{x}_{\mathbf{k}}$. Second, a residual or 'unexplained' factor $\left(\frac{G C \varepsilon}{\mu} / \mu\right)$, indicating the inequality in health variable that cannot be explained by selected explanatory factors across various socioeconomic groups. 
Table 1 Socio-economic and demographic profile of the study population by background characteristics, India, 2015-16

\begin{tabular}{|c|c|c|}
\hline Variables & Percentage & Sample \\
\hline \multicolumn{3}{|l|}{ Men's age (in years) } \\
\hline $15-19$ & 16.7 & 18,382 \\
\hline $20-29$ & 29.1 & 31,542 \\
\hline $30-39$ & 25.4 & 27,629 \\
\hline $40-49$ & 21.0 & 22,387 \\
\hline $50-54$ & 7.8 & 8321 \\
\hline \multicolumn{3}{|l|}{ Marital status } \\
\hline Never married & 36.0 & 39,692 \\
\hline Currently married & 64.0 & 68,569 \\
\hline \multicolumn{3}{|l|}{ Educational level } \\
\hline No Education & 13.1 & 14,545 \\
\hline Primary & 12.7 & 13,930 \\
\hline Secondary & 57.2 & 63,027 \\
\hline Higher & 17.1 & 16,759 \\
\hline \multicolumn{3}{|l|}{ Mass media } \\
\hline No exposure & 8.0 & 10,050 \\
\hline Exposure & 92.0 & 98,211 \\
\hline \multicolumn{3}{|l|}{ Body Mass Index } \\
\hline Underweight $(<18.5 \mathrm{~kg} / \mathrm{m} 2)$ & 19.7 & 20,760 \\
\hline Normal (18.5-24.99 kg/m2) & 60.7 & 68,238 \\
\hline Overweight ( $\geq 25$ kg/m2) & 19.5 & 19,093 \\
\hline \multicolumn{3}{|c|}{ Tobacco use (smoke/smokeless) } \\
\hline No & 54.2 & 55,024 \\
\hline Yes & 45.8 & 53,237 \\
\hline \multicolumn{3}{|l|}{ Caste } \\
\hline Scheduled caste & 19.9 & 19,257 \\
\hline Scheduled tribe & 8.9 & 19,354 \\
\hline Other backward class & 43.8 & 42,101 \\
\hline Others & 27.4 & 27,549 \\
\hline \multicolumn{3}{|l|}{ Religion } \\
\hline Hindu & 81.9 & 80,885 \\
\hline Muslim & 12.8 & 14,733 \\
\hline Others & 5.3 & 12,643 \\
\hline \multicolumn{3}{|l|}{ Wealth index } \\
\hline Poorest & 14.9 & 17,927 \\
\hline Poorer & 19.0 & 22,579 \\
\hline Middle & 21.2 & 23,562 \\
\hline Richer & 22.1 & 22,467 \\
\hline Richest & 22.8 & 21,726 \\
\hline \multicolumn{3}{|l|}{ Place of residence } \\
\hline Urban & 37.3 & 33,779 \\
\hline Rural & 62.7 & 74,482 \\
\hline Region ${ }^{\epsilon}$ & & \\
\hline
\end{tabular}

Table 1 Socio-economic and demographic profile of the study population by background characteristics, India, 2015-16 (Continued)

\begin{tabular}{lll}
\hline Variables & Percentage & Sample \\
\hline North & 14.1 & 23,777 \\
Central & 22.0 & 27,306 \\
East & 18.9 & 16,683 \\
Northeast & 3.3 & 13,924 \\
West & 18.1 & 11,725 \\
South & 23.7 & 14,846 \\
Total & $\mathbf{1 0 0 . 0}$ & $\mathbf{1 0 8 , 2 6 1}$
\end{tabular}

$€$ North: Chandigarh, Haryana, Himachal Pradesh, Jammu \& Kashmir, Delhi, Punjab, Rajasthan, Uttarakhand; Central: Chhattisgarh, Madhya Pradesh, Uttar Pradesh; East: Bihar, Jharkhand, Odisha, West Bengal; Northeast: Arunachal Pradesh, Assam, Manipur, Meghalaya, Mizoram, Nagaland, Sikkim, Tripura; West: Dadra \& Nagar Haveli, Daman \& Diu, Goa, Gujarat, Maharashtra; South: Andaman \& Nicobar Islands, Andhra Pradesh, Karnataka, Kerala, Lakshadweep, Puducherry, Tamil Nadu, Telangana

\section{Results}

Socioeconomic and demographic profile of the study population in India (Table 1)

About $17 \%$ of men belonged to $15-19$ years' age group, $64 \%$ were currently married, and $13 \%$ of men had no education. Majority of men (92\%) had mass media exposure, one-fifth of men were underweight (BMI-less than $18.5 \mathrm{~kg} / \mathrm{m}^{2}$ ), and about $46 \%$ of men used tobacco (smoke/smokeless). Nearly one-fifth of men belonged to scheduled caste, and $10 \%$ of men belonged to scheduled tribe caste. A higher proportion of men belonged to the Hindu religion, and around $63 \%$ of men lived in rural areas.

\section{Prevalence of anaemia among men by background} characteristics in India (Table 2)

The prevalence of anaemia was significantly higher among men who belonged to 15-19 (29\%) and 50-54 years' age group (30\%). Moreover, it was lowest among those who belonged to the 20-29 years' age group (18.9\%). Men's education and wealth quintile of the household had a negative association with the prevalence of anaemia. For instance, it was more prevalent among men who had no education (30.6\%) and lowest among those who had higher education (16.5\%). Similarly, the prevalence of anaemia was significantly higher among men who belonged to most impoverished families (32.5\%), and it was lowest among those who belonged to wealthiest families (17.5\%). Men who had no mass media exposure (32.2\%) had a significantly higher prevalence of anaemia compared to those who had media exposure (22.5\%). Anaemia was significantly higher among men who used tobacco (smoke/smokeless) (24.2\%) than those who did not use $(22.6 \%)$. Men who belonged to scheduled caste $(24.3 \%)$ and scheduled tribe $(32.4 \%)$ caste group had a higher prevalence of anaemia than other 
Table 2 Percentage distribution of anemia among men by background characteristics, India, 2015-16

\begin{tabular}{lll}
\hline Background Characteristics & Anaemia & $p$-value \\
\hline Men's age (in years) & & $p<0.001$ \\
$15-19$ & 29.2 & \\
$20-29$ & 18.9 & \\
$30-39$ & 21.0 & \\
$40-49$ & 24.9 & \\
$50-54$ & 30.3 &
\end{tabular}

Marital status

Never married

$p<0.001$

Currently married

23.6

23.2

Educational level

No Education

30.6

Primary

25.8

Secondary

23.1

Higher

Mass media

No exposure

Exposure

Body Mass Index

Underweight $(<18.5 \mathrm{~kg} / \mathrm{m} 2)$

Normal (18.5-24.99 kg/m2)

Overweight ( $\geq 25 \mathrm{~kg} / \mathrm{m} 2)$

Tobacco use (smoke/smokeless)

No

Yes

Caste

Scheduled caste

Scheduled tribe

Other backward class

Others

Religion

Hindu

Muslim

Others

Wealth index

Poorest

Poorer

Middle

Richer

Richest

Place of residence

Urban

Rural

Region ${ }^{\epsilon}$
Table 2 Percentage distribution of anemia among men by background characteristics, India, 2015-16 (Continued)

\begin{tabular}{lll}
\hline Background Characteristics & Anaemia & $\boldsymbol{p}$-value \\
\hline North & 20.4 \\
Central & 24.4 \\
East & 31.5 \\
Northeast & 24.9 \\
West & 19.6 \\
South & 20.2 \\
Total & $\mathbf{2 3 . 3}$ \\
\hline
\end{tabular}

$p<0.001$ based on chi-square test and Cochran Armitage trend test for ordered variables (education and wealth)

€North: Chandigarh, Haryana, Himachal Pradesh, Jammu \& Kashmir, Delhi, Punjab, Rajasthan, Uttarakhand; Central: Chhattisgarh, Madhya Pradesh, Uttar Pradesh; East: Bihar, Jharkhand, Odisha, West Bengal; Northeast: Arunachal Pradesh, Assam, Manipur, Meghalaya, Mizoram, Nagaland, Sikkim, Tripura; West: Dadra \& Nagar Haveli, Daman \& Diu, Goa, Gujarat, Maharashtra; South: Andaman \& Nicobar Islands, Andhra Pradesh, Karnataka, Kerala, Lakshadweep, Puducherry, Tamil Nadu, Telangana

caste groups. The prevalence of anaemia was significantly higher among men who lived in rural areas (25.9\%) compared to those who lived in urban counterparts (18.9\%). Moreover, the prevalence of anaemia $p<0.001$ among men was highest in the East region, and it was significantly lower in the South region.

\section{Estimates from logistic regression analysis for anaemia} among men in India (Table 3)

$p<0.001$ With reference to men aged 15-19 years' age group, the likelihood of anaemia was $30 \%$ and $23 \%$ less likely among men who belonged to 20-29 [OR: 0.70; CI: 0.66$p<0.0010 .73$ ] and 30-39 years [OR: 0.77; CI: 0.74-0.84] age group respectively and $20 \%$ more likely among those who belonged to 50-54 years age group [OR: 1.20; CI: 1.11-1.29]. Moreover, men who had primary [OR: 0.90; CI: 0.86-0.95], secondary [OR: 0.83; CI: 0.79-0.87] and higher education [OR: 0.71 ; CI: $0.66-0.75$ ] were $10 \%$, $p<0.001 \quad 17 \%$ and $29 \%$ less likely to have anaemia respectively compared to men who had no education. The odds of anaemia were $7 \%$ significantly less likely among men who had mass media exposure [OR: 0.93; CI: 0.89-0.98] than those who had no exposure. The likelihood of anaemia was significantly higher among men who were underweight [OR: 1.51; CI: 1.46-1.57] and lowered among those who were overweight [OR: 0.80; CI: 0.770.84] compared to men who had normal body mass index. The odds of anaemia were $33 \%$ more likely among men who belonged to the scheduled tribe group [OR: 1.33; CI: 1.26-1.40] compared to those who belonged to other caste groups. Household wealth had a negative relationship with anaemia among men. For instance, the odds of anaemia decreased with the increase in wealth quintile. Men who belonged to rural areas [OR: 1.12; CI: 1.08-1.16] had 12\% higher risk of anaemia 
Table 3 Estimates from logistic regression analysis for anaemia among men by their background characteristics, India, 2015-16

\begin{tabular}{l} 
Background Characteristic \\
\hline Men's age (in years) \\
$15-19$ \\
$20-29$ \\
$30-39$ \\
$40-49$ \\
$50-54$ \\
Marital status \\
Never married \\
Currently married \\
Educational level \\
No Education \\
Primary \\
Secondary \\
Higher \\
Mass media \\
No exposure \\
Exposure
\end{tabular}

OR $[95 \% \mathrm{Cl}]$

Ref.

$0.70^{* * *}(0.66-0.73)$

$0.77^{* * *}(0.74-0.84)$

$0.96(0.90-1.02)$

$1.20^{* * *}(1.11-1.29)$

Ref.

0.99(0.944-1.032)

Ref.

$0.90^{* * *}(0.86-0.95)$

$0.83^{* * *}(0.79-0.87)$

$0.71^{* * *}(0.66-0.75)$

Ref.

$0.93^{* * *}(0.89-0.98)$

Body Mass Index

Underweight $(<18.5 \mathrm{~kg} / \mathrm{m} 2)$

Normal $(18.5-24.99 \mathrm{~kg} / \mathrm{m} 2)$

Overweight ( $\geq 25 \mathrm{~kg} / \mathrm{m} 2$ )

Tobacco use (smoke/smokeless)

No

Yes

Caste

Scheduled caste

Scheduled tribe

Other backward class

Others

Religion

Hindu

Muslim

Others

\section{Wealth index}

Poorest

Poorer

Middle

Richer

Richest

Place of residence

Urban

Rural

Region $\epsilon^{\epsilon}$
$1.51^{* * *(1.46-1.57)}$

Ref.

$0.80^{* * *}(0.77-0.84)$

Ref.

$0.92^{* * *}(0.90-0.95)$

$0.97(0.92-1.01)$

$1.33^{* * *(1.26-1.40)}$

$0.97 *(0.93-1.00)$

Ref.

Ref.

$0.88^{* * *}(0.84-0.92)$

$0.97(0.92-1.02)$

Ref.

$0.90^{* * *}(0.86-0.94)$

$0.83^{* * *}(0.79-0.87)$

$0.78^{* * *}(0.73-0.82)$

$0.75^{* * *}(0.70-0.80)$

Ref.

$1.12^{* * *}(1.08-1.16)$

Table 3 Estimates from logistic regression analysis for anaemia among men by their background characteristics, India, 2015-16 (Continued)

\begin{tabular}{ll}
\hline Background Characteristics & OR [95\% Cl] \\
\hline North & Ref. \\
Central & $1.01(0.97-1.06)$ \\
East & $1.40^{* * *}(1.33-1.47)$ \\
Northeast & $0.75^{* * *}(0.70-0.79)$ \\
West & $0.87^{* * *}(0.83-0.93)$ \\
South & $0.93^{* *}(0.88-0.98)$ \\
\hline OR: Odds Ratio; Cl: confidence Interval; Ref: Reference category; ${ }^{* * *} p<0.001 ;$ \\
${ }^{* *} p<0.05 ;{ }^{*} p<0.10$ & \\
$€$ North: Chandigarh, Haryana, Himachal Pradesh, Jammu \& Kashmir, Delhi, \\
Punjab, Rajasthan, Uttarakhand; Central: Chhattisgarh, Madhya Pradesh, Uttar \\
Pradesh; East: Bihar, Jharkhand, Odisha, West Bengal; Northeast: Arunachal \\
Pradesh, Assam, Manipur, Meghalaya, Mizoram, Nagaland, Sikkim, Tripura; \\
West: Dadra \& Nagar Haveli, Damana \& Diu, Goa, Gujarat, Maharashtra; South: \\
Andaman \& Nicobar Islands, Andhra Pradesh, Karnataka, Kerala, Lakshadweep, \\
Puducherry, Tamil Nadu, Telangana
\end{tabular}

than those who belonged to urban ones. Moreover, the likelihood of anaemia was $40 \%$ more likely among men who belonged to East region [OR: 1.40; CI: 1.33-1.47] and $25 \%, 13 \%$ and $7 \%$ less likely among those who belonged to Northeast [OR: 0.75; CI: 0.70-0.79], West

[OR: 0.87; CI: 0.83-0.93], and South region [OR: 0.93; CI: 0.88-0.98] compared to those who belonged North region.

Estimates of decomposition analysis for the contribution of various explanatory variables for anaemia among men (Table 4)

Results from decomposition analysis revealed that wealth quintile explained $25.1 \%$ of the Socio-Economic Status (SES) related inequality followed by geographical regions of India (20.9\%), body mass index (17.8\%) and educational level (14.6\%) for anaemia among men in India. Additionally, place of residence, caste and mass media exposure explained SES related inequality for anaemia among men in India.

Figure 2 depicts the value of concentration index for anaemia among Indian states. The figure craves out the fact that which state has the highest inequality in terms of anaemia among men, which as a whole is concentrated among men from poor wealth quintile. Highest inequality was witnessed in Mizoram $(-0.190)$ followed by Telangana $(-0.190)$, Odisha $(-0.187)$ and Rajasthan $(-0.165)$ whereas the lowest inequality was recorded in Goa (0.014), followed by Haryana $(-0.015)$, Karnataka $(-0.032)$ and Jammu \& Kashmir $(-0.043)$.

Figure 3 depicts the concentration curve for anaemia among men across six geographical regions of India. The curve above the line of equality shows that anaemia was concentrated among men from low socioeconomic status. The negative value of the concentration index 
Table 4 Estimates of decomposition analysis for the contribution of various explanatory variables for anaemia among men in India, 2015-16

\begin{tabular}{|c|c|c|c|c|c|c|}
\hline Background Characteristics & Coefficient & Elasticity & $\mathrm{Cl}$ & Absolute contribution to $\mathrm{Cl}$ & Percentage contribution & $\%$ \\
\hline \multicolumn{7}{|l|}{ Men's age (in years) } \\
\hline \multicolumn{7}{|l|}{ 15-19(Ref.) } \\
\hline $20-29$ & $-0.360^{* * *}$ & -0.020 & 0.010 & 0.000 & 0.7 & \\
\hline $30-39$ & $-0.240^{* * *}$ & -0.012 & -0.002 & 0.000 & -0.1 & \\
\hline $40-49$ & -0.042 & -0.003 & 0.016 & 0.000 & 0.2 & \\
\hline $50-54$ & $0.179 * * *$ & 0.003 & 0.043 & 0.000 & -0.4 & \\
\hline \multicolumn{7}{|l|}{ Marital status } \\
\hline \multicolumn{6}{|l|}{ Never married (Ref.) } & \\
\hline Currently married & -0.013 & 0.001 & -0.013 & 0.000 & 0.0 & \\
\hline
\end{tabular}

Educational level

No Education (Ref.)

Primary

$-0.102^{* * *}-0.003$

$-0.278$

0.001

Secondary

$-0.184^{* * *}$

$-0.019$

$0.030 \quad-0.001$

$-3.3$

Higher

$-0.349^{* * *} \quad-0.010$

$0.440-0.005$

Mass media

No exposure (Ref.)

Exposure

$$
-0.068^{* * *}
$$

$-0.014$

0.054

$-0.001$

Body Mass Index

Underweight (<18.5 kg/m2)

$0.411^{* * *}$

0.016

$-0.219$

$-0.003$

11.9

Normal (18.5-24.99 kg/m2)(Ref.)

Overweight ( $\geq 25 \mathrm{~kg} / \mathrm{m} 2)$

$-0.222^{* * *} \quad-0.006$

$0.309-0.002$

5.9

Tobacco use (smoke/smokeless)

No (Ref.)

Yes

$-0.079^{* * *}$

$-0.004$

$-0.149$

0.001

\section{Caste}

Scheduled caste

$$
\begin{array}{ll}
-0.036 \quad 0.001
\end{array}
$$

$-0.157$

0.000

Scheduled tribe

$0.283^{* * *}$

0.006

$-0.420$

$-0.002$

Other backward class

$-0.036^{*}$

0.001

0.014

0.000

$$
-2.2
$$

Others (Ref.)

\section{Religion}

Hindu (Ref.)

$0.038 \quad 0.000$

Muslim

$-0.130^{* * *}$

$-0.003$

0.229

0.000

0.3

Wealth index

Poorest (Ref.)
Poorer
Middle
Richer
Richest

Place of residence

Urban (Ref.)

$$
\text { Rural }
$$

$-0.033$

0.001$$
\text { . }
$$

$$
\text { (2) }
$$

4 
Table 4 Estimates of decomposition analysis for the contribution of various explanatory variables for anaemia among men in India, 2015-16 (Continued)

\begin{tabular}{llllll}
\hline Background Characteristics & Coefficient & Elasticity & $\mathrm{Cl}$ & Absolute contribution to Cl & Percentage contribution \\
\hline North (Ref.) & & & & & 1.9 \\
Central & 0.012 & 0.003 & -0.161 & -0.001 & 17.9 \\
East & $0.334^{* * *}$ & 0.015 & -0.339 & -0.005 & 0.4 \\
Northeast & $-0.294^{* * *}$ & 0.000 & -0.253 & 0.000 & 1.1 \\
West & $-0.134^{* * *}$ & -0.002 & 0.156 & 0.000 & -0.3 \\
South & $-0.070^{* *}$ & 0.001 & 0.186 & 0.000 & $-\mathbf{0 . 0 2 9}$ \\
Calculated Cl & & & & $-\mathbf{0 . 1 2 1}$ & \\
Actual Cl & & & & $-\mathbf{0 . 0 9 2}$ & \\
Residual & & & & &
\end{tabular}

Cl: concentration Index; Ref: Reference category; ${ }^{* *} p<0.001 ;{ }^{* *} p<0.05 ;{ }^{*} p<0.10 ; \%$ : percentage

$€$ North: Chandigarh, Haryana, Himachal Pradesh, Jammu \& Kashmir, Delhi, Punjab, Rajasthan, Uttarakhand; Central: Chhattisgarh, Madhya Pradesh, Uttar Pradesh; East: Bihar, Jharkhand, Odisha, West Bengal; Northeast: Arunachal Pradesh, Assam, Manipur, Meghalaya, Mizoram, Nagaland, Sikkim, Tripura; West: Dadra \& Nagar Haveli, Daman \& Diu, Goa, Gujarat, Maharashtra; South: Andaman \& Nicobar Islands, Andhra Pradesh, Karnataka, Kerala, Lakshadweep, Puducherry, Tamil Nadu, Telangana

depicts that the outcome variable (anaemia among men) is concentrated among the poor. The value of CI for India was $(-0.12)$, which depicts pro-rich bias of anaemia among men. The highest inequality was witnessed in south and north-eastern region $(-0.11)$ followed by eastern and western region (-0.10) of India, while lowest inequality was observed in north $(-0.05)$ and central $(-0.09)$ regions.

\section{Discussion}

Anaemia is a major public health problem affecting 1.62 billion people worldwide. Although the prevalence of anaemia is estimated at $9 \%$ in countries with high development, in countries with low development the prevalence is $43 \%$ [4]. Research on anaemia in developing countries like Uganda [32], Bangladesh [33-35], Sri Lanka [36, 37] mostly concentrates on children and women. Studies in India are no different $[19,38]$ except a few $[15,25]$.
Hence, majorly overlooking men in the population and creating a void in the policies that focus on anaemia.

To overcome this, the present research investigates socioeconomic inequality in anaemia among men aged 15-54 years in India by utilizing the fourth round of the National Family Health Survey. The study found that men in the age group 50-54 years, with no education and mass media exposure, who were underweight (< $18.5 \mathrm{~kg} / \mathrm{m} 2$ ), belonged to the schedule tribe, were from poorest wealth quintile, lived in rural areas, and eastern region of the country had a higher likelihood of anaemia. The results from decomposition analysis further strengthened these findings by showing the contribution of each of the socio-economic characteristics towards men having anaemia. For instance, the majority of the SES related inequality was explained by wealth quintile followed by geographical regions of India, body mass index and educational attainment. 


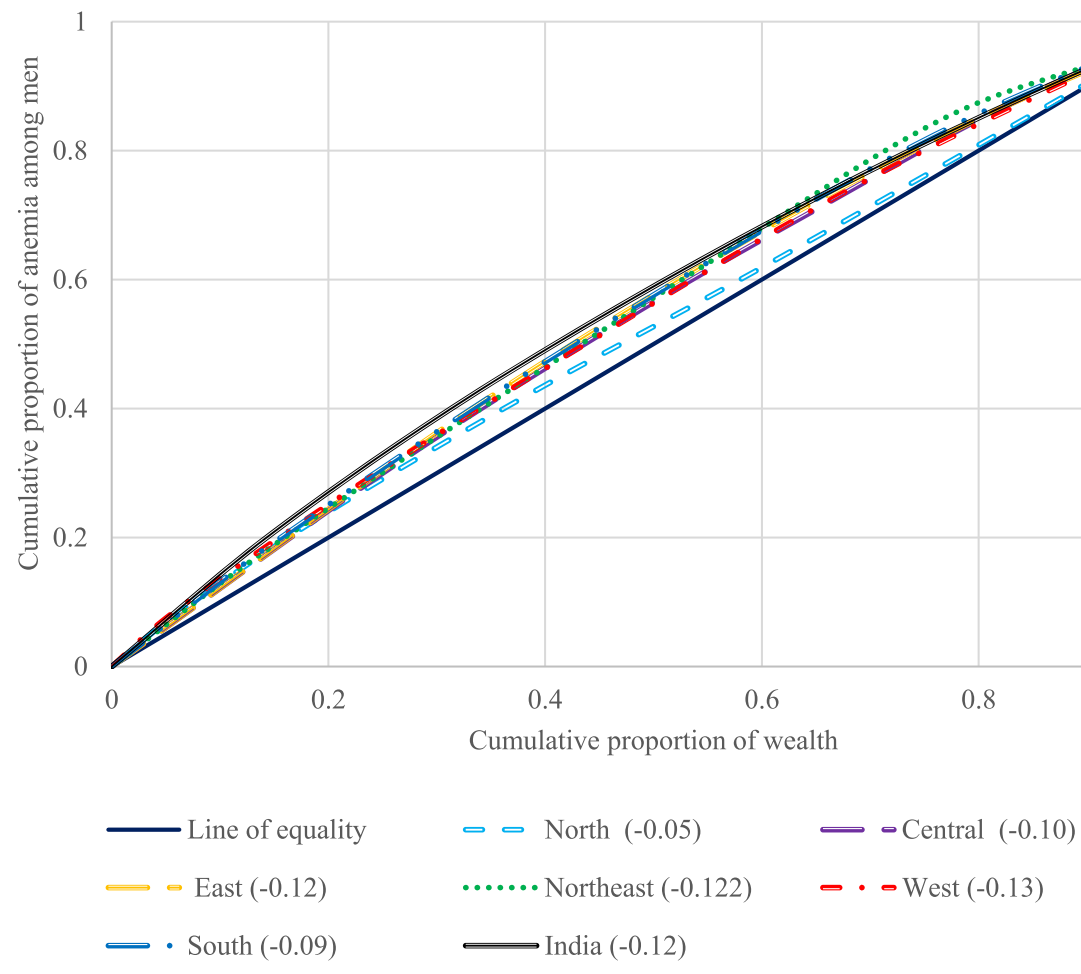

Fig. 3 Concentration curve for anaemia among men in India by regions

A recent study on anaemia among men in India found similar findings on the socio-demographic factors at the individual level [25]. In rural Punjab, Gupta et al. found that both males and females who were underweight, and who belonged to a lower socio-economic status had higher prevalence of anaemia [39]. Research in China, Peru, Egypt, and the US suggest that a higher intake of vitamin $\mathrm{C}$ and iron by overweight and obese women might partly be the cause of the discrepancy between anaemia and BMI status [40-42]. However, since the results are based on women, any speculation about anaemia \& BMI status of men should be interpreted with caution. A study in the US found that rates of anemia in men increased monotonically with age [43] . Further, a community-based cross-sectional survey in rural Haryana, India indicated a positive relationship between age of men and their anaemia prevalence [5]. An increase in proportion of normocytic anaemia might suggest the high prevalence of anaemia in male adults as their age increases [44].

The study findings specified the significant role of wealth quintile in SES related inequality in anaemia prevalence among men in India, and the finding is similar to another study [18]. In India, men belonging to the poorest wealth quintile from the states of Mizoram, Telangana, Odisha and Rajasthan suffer from the highest inequality in terms of anaemia. Further, the concentration index and concentration curve show that anaemia prevalence in men is highly concentrated among the poor in the north-eastern, eastern and western region of the country. The inter-relationships between poverty and malnutrition are well explained in previous studies. Evidence shows that malnutrition produces conditions of poverty by reducing the economic potential of the population and likewise, poverty reinforces malnutrition by increasing the risk of food insecurity [45]. Similarly in India, poverty restricts access to food that is required to meet daily requirements or to ensure dietary diversity, that leads to malnutrition, which again adversely affects educational and economic attainments, thus perpetuating poverty [46]. In fact, studies have shown the economic costs of anaemia in terms of lost schooling and lost productivity $[7,11]$. Therefore, policymakers should include men belonging to poorest households and with low BMI in the target population to achieve an anaemia free India.

Education also plays a crucial role in explaining the SES related inequality. The present study revealed that men who had no education were more likely to be anaemic. The result is consistent with studies that examine similar results for women [32, 35, 39, 47]. Evidence indicates that education can change knowledge, attitudes, and practice, thereby improving nutritional status [4852]. Moreover, a high level of individual educational also helps in being more receptive to the advice given by the health staff [53]. As individual level of education is 
important in addressing the problem of anaemia, so is awareness about it. For instance, results from a focus group discussion conducted on adult male members revealed that although men were aware of iron tablets used for treating anaemia but thought it was provided only to pregnant women by the health system [12]. To avoid such ignorance, WHO recommends health and other community infrastructures to organize comprehensive education and information program that motivates people to take iron tablets [54].

Despite the continuous effort of the Government of India to eliminate anaemia, the results emphasize that burden of anaemia exists in India. Previously, the government has undertaken various policies, for instance, the National Nutritional Anaemia Prevention Program, National Iron Plus Initiative, Anaemia Mukt Bharat. However, most of the policies focused on pregnant women, children and adolescents and hence the inequality. Our study results emphasize that older men also belong to the high-risk groups, and therefore the existing programs should be extended to include men. Community health workers (i.e., Accredited Social Health Activists) can promote awareness about anaemia through household visits and community meetings.

\section{Acknowledgements}

We express our sincere gratitude to Shobhit Srivastava, PhD research scholar International Institute for Population Science for his technical support and expertise.

The survey/questionnaire is a standard survey/questionnaire, that has previously been published. Kindly refer to http://rchiips.org/NFHS/NFHS4/ schedules/NFHS-4Mans.pdf

\section{Authors' contributions}

Pradeep Kumar: Conceptualization, Methodology, Validation, Software, Supervision. Himani Sharma: Writing - original draft, Validation. Debashree Sinha: Writing - review \& editing, Supervision, Validation. The author(s) read and approved the final manuscript.

\section{Funding}

No funding is received for the present research.

\section{Availability of data and materials}

The data used in the present study is available on https://dhsprogram.com/ data/available-datasets.cfm.

\section{Declaration}

\section{Ethics approval and consent to participate}

Our study is based on a secondary data set with no identifiable information on the survey participants. This data set is available in public domain for research use and hence, no approval was required from any institutional review board. Further, in NFHS-4, blood specimens for anaemia testing were not collected by the authors but by trained health investigators with the consent of the respondents. More details on how haemoglobin was measured can be found in the national report http://rchiips.org/nfhs/pdf/NFHS4/ India.pdf

\section{Consent for publication}

Not Applicable.

\section{Competing interests}

We do not have any competing interest.

\section{Author details}

'Department of Mathematical Demography \& Statistics, International Institute for Population Sciences, Mumbai, Maharashtra 400088, India. ${ }^{2}$ Department of Development Studies, International Institute for Population Sciences,

Mumbai, Maharashtra 400088, India.

Received: 6 December 2020 Accepted: 23 June 2021

Published online: 07 July 2021

\section{References}

1. Development Initiatives 2017. The global nutrition report 2017: nourishing the SDGs. Bristol: Development Initiatives; 2017.

2. Kassebaum NJ, Fleming TD, Flaxman A, Phillips DE, Steiner C, Barber RM, et al. The global burden of Anemia. Hematol Oncol Clin North Am [Internet]. 2016;30(2):247-308. Available from:. https://doi.org/10.1016/j.hoc.2 015.11.002.

3. GlobalData. India has highest prevalence of anemia among 16 major pharma markets, finds GlobalData - GlobalData. Available from: https:// www.globaldata.com/india-highest-prevalence-anemia-among-16-major-pha rma-markets-finds-globaldata/

4. McLean E, Cogswell M, Egli I, Wojdyla D, De Benoist B. Worldwide prevalence of anaemia, WHO vitamin and mineral nutrition information system, 1993-2005. Public Health Nutr. 2009;12(4):444-54. https://doi.org/1 $0.1017 / 51368980008002401$

5. International Institute for Population Sciences (IIPS) and ICF. National Family Health Survey (NFHS-4), 2015-16: India. Mumbai: IIPS. 2017.

6. Sunuwar DR, Singh DR CN, Pradhan PMS, Rai P TK. Prevalence and factors associated with anemia among women of reproductive age in seven South and Southeast Asian countries: Evidence from nationally representative surveys. PLoS One. 2020;15(8):e0236449.

7. Alderman H, Linnemayr S. Anemia in low-income countries is unlikely to be addressed by economic development without additional programs. Food Nutr Bull. 2009;30(3):265-9. https://doi.org/10.1177/156482650903000308.

8. Subramanyam MA, Kawachi I, Berkman LF SS. Is Economic Growth Associated with Reduction in Child Undernutrition in India? PLoS Med. 2011;8(3):e1000424.

9. Nair KM, lyengar V. Iron content, bioavailability \& factors affecting iron status of Indians. Indian J Med Res. 2009;(November):634-45.

10. Basta SS, Soekirman, Karyadi D, Scrimshaw NS. Iron deficiency of adult males anemia and the productivity in Indonesia. Am J Clin Nutr. 1979;(March):91625.

11. Horton S, Ross J. The economics of iron deficiency. Food Policy. 2003;28(1): 51-75. https://doi.org/10.1016/S0306-9192(02)00070-2.

12. Kant S, Kumar R, Malhotra S, Kaur R, Haldar P. Prevalence and determinants of anemia among adult males in a rural area of Haryana, India. J Epidemiol Glob Health. 2019;9(2):128-34. https://doi.org/10.2991/jegh.k.190513.001.

13. Ministry of Human Resource Development (MHRD), National Nutrition Policy: 1993. Government of India, New Delhi.

14. Welfare M of health and family. Guidelines for Control of Iron Deficiency Anaemia. 2013;54

15. Kumar P, Sharma H, Patel KK. Prevalence and risk factors of anaemia among men: a study based on empowered action group states, India. Nutr Health. 2021;27(2):1-8.

16. Bhatia VSD. And PS. India steps ahead to curb anemia: Anemia Mukt Bharat. Indian J Community Heal. 2018;30(4):312-6.

17. Khatun T, Alamin A, Saleh F, Hossain M, Hoque A, Ali L. Anemia among garment factory Workers in Bangladesh. Middle East J Sci Res. 2013;16(4): $502-7$.

18. Jose $\mathrm{S}$. Adult undernutrition in India : is there a huge gender gap ? The incidence of undernutrition among women in India. 2011;46(29):95-102.

19. Sharma H, Singh SK, Srivastava S. Socio-economic inequality and spatial heterogeneity in anaemia among children in India: evidence from NFHS-4 (2015-16). Clin Epidemiol Glob Heal. 2020;(December 2019):1-14. Available from: https://doi.org/10.1016/j.cegh.2020.04.009.

20. Sharma H, Singh SK, Srivastava S. major Correlates of Anemia among Women (Age 15-49) in India and Spatial Variation, Evidence from National Family Health Survey-4. J Women's Health Care. 2018;07(04):2167-0420.

21. Davies CTM, Chukweumeka AC, Van Haaren JPM. Iron deficiency anaemia: its effect on maximum aerobic power and responses to exercise in African males aged 17-40 years. Clin Sci. 1973:44(6):555-62. https://doi.org/10.1042/ cs0440555. 
22. Jamil KM, Rahman AS, Bardhan PK, Khan Al. Micronutrients and Anaemia Author ( s ): Kazi M . Jamil, Ahmed Shafiqur Rahman, P. K. Bardhan Ashraful Islam Khan, Fahima Chowdhury, Shafiqul Alam Sarker, Ali Miraj Khan and Tahmeed Ahmed Source. J Health Popul Nutr. 2019;26(3):340-55.

23. Kim NH, Park JH, Park D II, Sohn C II, Choi K, Jung YS. Should asymptomatic young men with iron deficiency anemia necessarily undergo endoscopy? 2018;33(6):1084-92.

24. Didzun O, De Neve J, Awasthi A, Dubey M, Theilmann M, Bärnighausen T, et al. Articles Anaemia among men in India : a nationally representative cross-sectional study. Lancet Glob Heal. 2019;7(12):e1685-94. Available from: https://doi.org/10.1016/S2214-109X(19)30440-1.

25. Didzun O, De Neve JW, Awasthi A, Dubey M, Theilmann M, Bärnighausen T, et al. Anaemia among men in India: a nationally representative crosssectional study. Lancet Glob Heal. 2019;7(12):e1685-94. https://doi.org/10.1 016/S2214-109X(19)30440-1.

26. Marcoulides KM, Raykov T. Evaluation of variance inflation factors in regression models using latent variable modeling methods. Educ Psychol Meas. 2019;79(5):874-82. https://doi.org/10.1177/0013164418817803.

27. Wagstaff A, Paci P van DE. On the measurement of inequalities in health. Soc Sci Med. 1991;33(5):545-57.

28. Patel R, Kumar P, Srivastava S, Chauhan S. Change in socio-economic inequality of tobacco consumption among men in India: evidence from National Family Health Survey 2005-06 to 2015-16. J Subst Use. 2020;00(00): 1-9. Available from: https://doi.org/10.1080/14659891.2020.1846217.

29. Chauhan S, Sekher T V., Kumar P, Srivastava S, Patel R. Prevalence, determinants and socio-economic inequality of early marriage among men in India. Child Youth Serv Rev [internet]. 2020;116(may):105273. Available from: https://doi.org/10.1016/j.childyouth.2020.105273.

30. O'donnell O, Van Doorslaer E, Wagstaff A, Lindelow M. Analyzing health equity using household survey data: a guide to techniques and their implementation. The World Bank; 2007, DOl: https://doi.org/10.1596/978-08213-6933-3.

31. Wagstaff A, Paci $P$, van Doorslaer E. On the measurement of inequalities in health. Soc Sci Med. 1991;33(5):545-57. https://doi.org/10.1016/0277-9536(91 )90212-U.

32. Kikafunda JK, Lukwago FB, Turyashemererwa F. Anaemia and associated factors among under-fives and their mothers in Bushenyi district, Western Uganda. Public Health Nutr. 2009;12(12):2302-8. https://doi.org/10.1017/S13 68980009005333.

33. Yusuf A, Mamun ASMA, Kamruzzaman M, Saw A, Abo El-Fetoh NM, Lestrel $P E$, et al. Correction to: factors influencing childhood anaemia in Bangladesh: a two level logistic regression analysis. BMC Pediatr. 2019;19(1): 1-9. https://doi.org/10.1186/s12887-019-1581-9.

34. Hyder SZ, Persson L-Å, Chowdhury M, Lönnerdal B, Ekström E-C. Anaemia and iron deficiency during pregnancy in rural Bangladesh. Public Health Nutr. 2004;7(8):1065-70. https://doi.org/10.1079/PHN2004645.

35. Hyder SZ, Persson L-Å, Chowdhury A, Ekström E-C. Anaemia among nonpregnant women in rural Bangladesh. Public Health Nutr. 2001;4(1):79-83. https://doi.org/10.1079/PHN200055.

36. Thoradeniya T, Wickremasinghe R, Ramanayake R, Atukorala S. Low folic acid status and its association with anaemia in urban adolescent girls and women of childbearing age in Sri Lanka. Br J Nutr. 2006;95(3):511-6. https:// doi.org/10.1079/BJN20051590.

37. Allen A, Allen S, Rodrigo R, Perera L, Shao W, Li C, et al. Iron status and anaemia in Sri Lankan secondary school children: a cross-sectional survey. PLoS One. 2017;12(11):1-14.

38. Gupta S, Agarwal S, Gupta V, Kaushal R, Jain A, Khare N. Prevalence of Anemia among rural population living in and around of rural health and training center, Ratua Village of Madhya Pradesh. Muller J Med Sci Res. 2014;5(1):15. https://doi.org/10.4103/0975-9727.128936.

39. Gupta VK, Maria AK, Kumar R, Bahia JS, Arora S. To study the prevalence of anaemia in young males and females with respect to the age, body mass index (BMI), activity profile and the socioeconomic status in rural Punjab. J Clin Diagnostic Res. 2011;5(5):1020-6.

40. Eckhardt CL, Torheim LE, Monterrubio E, Barquera S, Ruel MT. The overlap of overweight and anaemia among women in three countries undergoing the nutrition transition. Eur J Clin Nutr. 2008;62(2):238-46. https://doi.org/10.103 8/sj.ejcn.1602727.

41. Ausk KJ, loannou GN. Is obesity associated with anemia of chronic disease? A population-based study. Obesity. 2008;16(10):2356-61. https://doi.org/10.1 038/oby.2008.353.
42. Qin Y, Melse-Boonstra A, Pan X, Yuan B, Dai Y, Zhao J, et al. Anemia in relation to body mass index and waist circumference among chinese women. Nutr J [internet]. 2013;12(1):1.

43. Le CHH. The prevalence of anemia and moderate-severe anemia in the US population (NHANES 2003-2012). PLoS One. 2016;11(11):1-14. Available from:. https://doi.org/10.1371/journal.pone.0166635.

44. Alvarez-Uria G, Naik PK, Midde M, Yalla PS, Pakam R. Prevalence and severity of anaemia stratified by age and gender in rural India. Anemia. 2014;2014:15. https://doi.org/10.1155/2014/176182.

45. Siddiqui F, Salam RA, Lassi ZS, Das JK. The intertwined relationship between malnutrition and poverty. Front Public Heal. 2020;8(August):1-5.

46. Varadharajan KS, Thomas T, Kurpad AV. Poverty and the state of nutrition in India. Asia Pac J Clin Nutr. 2013;22(3):326-39. https://doi.org/10.6133/apjen.2 013.22.3.19

47. Balarajan Y, Ramakrishnan U, Özaltin E, Shankar AH, Subramanian SV. Anaemia in low-income and middle-income countries. Lancet. 2011; 378(9809):2123-35 Available from: https://doi.org/10.1016/S0140-6736(1 0)62304-5.

48. Noronha JA, Bhaduri A, Bhat HV, Kamath A. Interventional study to strengthen the health promoting behaviours of pregnant women to prevent anaemia in southern India. Midwifery. 2013;29(7):e35-41 Available from: https://doi.org/10.1016/j.midw.2012.07.014

49. Anand T, Medicine C, Rahi M, Medicine C, Sharma P, Medicine C, et al. Issues in prevention of iron deficiency anaemia in India. Nutrition.2014;70(78):764-70 Available from: https://doi.org/10.1016/j.nut.2013.11.022.

50. Jalambo MO, Sharif R, Naser IA, Karim NA. Improvement in knowledge, attitude and practice of Iron deficiency Anaemia among Iron-deficient female adolescents after nutritional educational intervention. Glob J Health Sci. 2017;9(7):15. https://doi.org/10.5539/gjhs.v9n7p15.

51. Eftekhar Ardebili $H$, Bagheri $F$, Shahnazi $H$. The effect of PRECEDE model in preventing iron deficiency anemia in high school students. J Res Heal. 2018; 8(4):339-45.

52. Abu-Baker NN, Eyadat AM, Khamaiseh AM. The impact of nutrition education on knowledge, attitude, and practice regarding iron deficiency anemia among female adolescent students in Jordan. Heliyon. 2021;7(2): e06348

53. Lokare P, Gattani P, Karanjekar V, Kulkarni A. A study of prevalence of anemia and sociodemographic factors associated with anemia among pregnant women in Aurangabad city, India. Ann Niger Med. 2012;6(1):30. https://doi.org/10.4103/0331-3131.100213.

54. WORLD HEALTH ORGANIZATION. Iron Deficiency Anaemia Assessment, Prevention, and Control. 2001.

\section{Publisher's Note}

Springer Nature remains neutral with regard to jurisdictional claims in published maps and institutional affiliations.

\section{Ready to submit your research? Choose BMC and benefit from:}

- fast, convenient online submission

- thorough peer review by experienced researchers in your field

- rapid publication on acceptance

- support for research data, including large and complex data types

- gold Open Access which fosters wider collaboration and increased citations

- maximum visibility for your research: over $100 \mathrm{M}$ website views per year

At BMC, research is always in progress.

Learn more biomedcentral.com/submission 